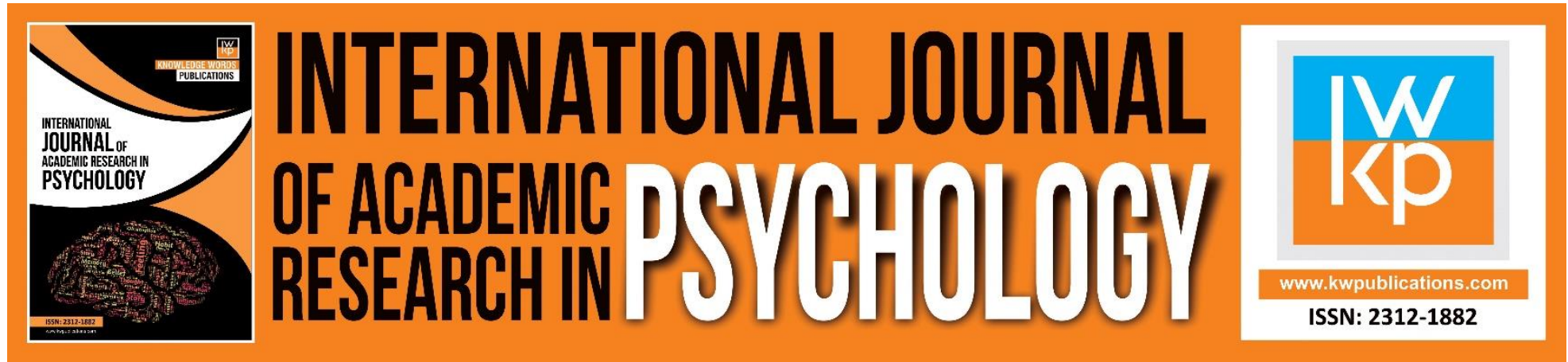

\title{
Body Image Predictors in Post-Mastectomy among Adult Breast Cancer Patients
}

\section{Osama Hasan Gaber}

To Link this Article: http://dx.doi.org/10.46886/IJARP/v7-i1/7258

DOI: $10.46886 / I J A R P / v 7-i 1 / 7258$

Received: 18 April 2020, Revised: 20 May 2020, Accepted: 19 June 2020

Published Online: 30 June 2020

In-Text Citation: (Gaber, 2020)

To Cite this Article: Gaber, O. H. (2020). Body Image Predictors in Post-Mastectomy among Adult Breast Cancer Patients. International Journal of Academic Research in Psychology, 7(1), 46-59.

Copyright: (C) 2020 The Author(s)

Published by Knowledge Words Publications (www.kwpublications.com)

This article is published under the Creative Commons Attribution (CC BY 4.0) license. Anyone may reproduce, distribute, translate and create derivative works of this article (for both commercial and non-commercial purposes), subject to full attribution to the original publication and authors. The full terms of this license may be seen at: http://creativecommons.org/licences/by/4.0/legalcode

Vol. 7, No. 1, 2020, Pg. 46 - 59

https://kwpublications.com/journals/journaldetail/IJARP

JOURNAL HOMEPAGE

Full Terms \& Conditions of access and use can be found at https://kwpublications.com/pages/detail/publication-ethics 


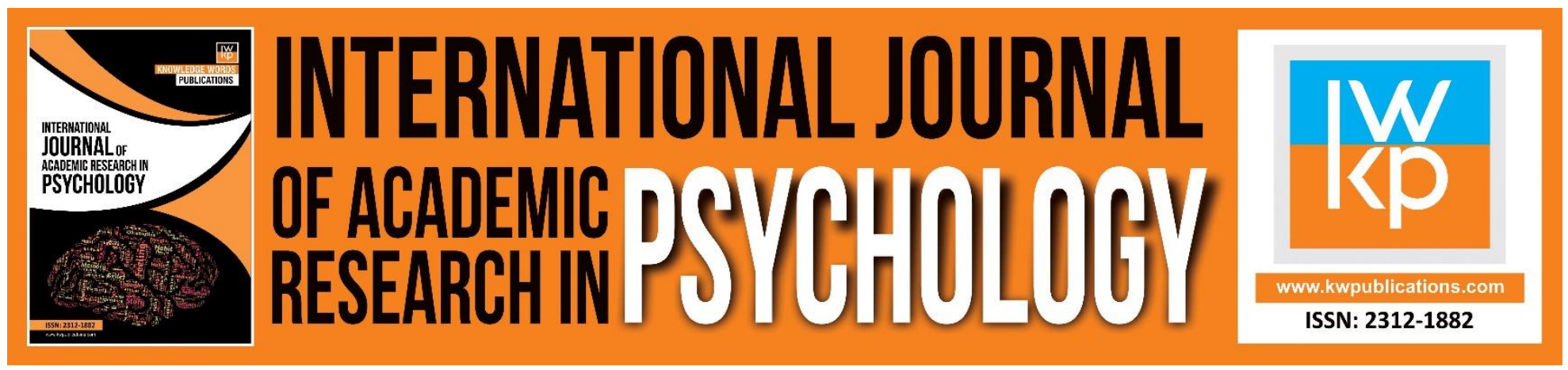

\title{
Body Image Predictors in Post-Mastectomy among Adult Breast Cancer Patients
}

\author{
Dr. Osama Hasan Gaber \\ Associate Professor of Psychology, Faculty of Education, Najran University, Saudi Arabia \\ Associate Professor of Psychology, Department of Education and Psychology, Faculty of Education, \\ Najran University, Saudi Arabia, P.O. Box: 1988, Najran, Saudi Arabia. \\ Email: dr.osamagaber@yahoo.com
}

\begin{abstract}
This study aimed to examine the relationship between Body Image, depressive symptoms, selfesteem and emotional stress with Husband for (33) adult women Breast Cancer patients. (Body Image scale, depressive symptoms scale and emotional distress scale (prepared by the Author) and self Esteem scale (Rosenberg). Were used Pearson Correlation coefficient showed that there is statistically significant relationship between body Image and depressive symptoms (0.409). In addition to showed that there is statistically significant relationship between Body Image and Selfesteem (-0.376). Also, the result showed that there is statistically significant relationship between body Image and emotional stress with husband (0.429). Also, the regression and prediction coefficient (stepwise) were also used and showed two models, the first model explains that the emotional stress with husband predicts Body Image, the second model explains that emotional stress with husband and depressive symptoms predicts Body Image.
\end{abstract}

Keywords: Body Image, Depressive Symptoms, Self Esteem, Emotional Stress.

\section{Introduction}

Breast cancer is one of the four most incessant sorts of tumor found in women's and the second driving reason for death from cancer. As all through whatever remains of the world, regarding surgeries, altered radical mastectomy was the most widely recognized medical procedure (63\%), and bosom moderating medical procedure was the second (36\%). Just $1 \%$ of patients had radical mastectomy. Mastectomy, as the careful treatment of bosom disease, results in a lasting change to the presence of ladies. The bosom is viewed as a piece of a lady's character in numerous societies; it speaks to gentility, sexuality, excellence, parenthood, and sustaining newborn children. The apparent loss of any of these ascribes may prompt a negative change in body image (Kocan \& Gürsoy, 2016).

Obvious changes in women' self-perception are joined by negative mental results. A man's psychological picture of oneself is implicitly showed in one's esteem reactions and Since a man's view of his/her body greatly affects his/her character and conduct, an adverse self-perception prompts 
antagonistic mental impacts, which unavoidably influence one's disposition and relationships with others (Bagheri \& Mazaheri, 2015).

Mastectomy is one of the basic medications for this tumor, in which bosom is expelled with or without lymph hubs. women who experience mastectomy encounter medical procedure physical deformities and physical and mental dangers because of tumor which can prompt mental injury, for example, depression and anxiety. However, inquiries about show that seeing data needs and meeting them prompt their self-care enhancement and decrease the effects of these dangers as well as prompt their adapting to ailment, better communication amid and after treatment, accomplishment in selfcare, and having a decent life after surgery. Thus, focusing on these patients' data needs amid postsurgery care period appears to be essential to reach to better result in the briefest time (Latifi, Salimi, Barahmand, Fahimnia, \& Farsani, 2018).

The author believes that after mastectomy, women may feel negative emotions as result for the features changing of her body, which leads to Some negative psychological feelings such as Such as anxiety and depression and fear of non-acceptance from others. Studies have shown that many. The author believes that the body image is one of the most disturbing subjects of breast cancer patients after the stage of mastectomy for many reasons, including external appearance and relationship with the partner of life and a sense of femininity.

Body image is regularly striking in women's breast cancer encounters. Because breast cancer treatment more often than not impacts a women's appearance and saw gentility, restorative researchers have been worried about how women see and assess their bodies after cancer treatment (Fang, Chang, \& Shu, 2014). The researcher believes that the perception of the image of sting in breast cancer patients after the stage of mastectomy is very important for women.

The author believes that there are many factors and reasons responsible for the perception of the negative body image after the stage of mastectomy Such as psychological symptoms and self-esteem for the patient and Type of relationship with husband. Depression symptoms are one of the factors that may be associated with the body image of cancer patients, especially after the stage of mastectomy. Where the patient feels the desire for isolation and the feeling of despair and frustration because of the pessimistic view of her life after the eradication the femininity symbol. This is confirmed by the results of several studies(Hamilton, 2008; Holsen, Kraft, \& Røysamb, 2001; Junne et al., 2016; Manaf, Saravanan, \& ZuhrAh, 2016).

The author believe that the mastectomy of cancer patients greatly affects their self-esteem, where the patient feels a kind of self-intolerance because of the internal feeling that others do not accept her and her body and this may affect her perception of body image.

According to Carl Rogers' self-theory, a person who has a positive self esteem has the ability to coping frustrations, feelings of helplessness and anxiety. Because self-esteem makes a person able to continue life and has a high sense that the future will bring him positive news and optimism in addition to self-acceptance. The results of the study (Leite, Nogueira, \& Terra, 2015) showed that women cancer patients women who have a positive self esteem continue to receive treatment in a systematic manner.

Thus, for some couples, the wife's cancer experience can lead to great difficulties in adaptation and relationship, which may lead to greater feelings of conflict and less intimacy (Zimmermann, 2015).

Breast Cancer has long been seen as an individual stress experience that must be confronted with individual coping strategies. 
The author believes that the removal of the wife to one of her breasts as a result of breast cancer effects on intimate or emotional relationship between husband and wife. Because the breast is one of the factors of sexual arousal of the husband. Which leads to the wife feeling a sense of frustration because she lost one of the members of her body, which works to raise and stir her husband during the intimate relationship, the difficult feelings may lead to disorder perception of body image. In addition, women's in post mastectomy as a result to cancer may make them feel disappointed because they feel less attractive after losing one of their breasts, which can lead to upsetting intimacy with their partners or husbands, which causes the negative body's image. In addition to the breast is not just a gland that receives hormonal effects, but it is an area of great interest in most cultures because it is part of the female body image and has a great undeniable value for both the infected patient women and her husband (Arroyo \& López, 2011).

Also (Diji et al., 2015) study showed that the mastectomy affects men's perception of their wives' body image, emotional and intimate life, and coping mechanisms. This leads to feelings of frustration and dysfunctional in emotional and intimate relationship between husband and wife, which may cause disturbance of the body image of the wife.

The author wants to present some of the difficulties he faced in that study such as difficulty in obtaining the sample because of the psychological feelings that the patient has mastectomy, where he feels the reluctance and unwillingness to participate in the application of some of the scales that prepared by the author for that study. In addition to this study also contained some of the scales that indicated some special relations such as intimacy and emotional relationship between the husband and wife, which caused awkwardness to some study sample.

\section{Study Questions}

Accordingly, this study aimed to explore the Predictive relationship between the negative body image and, Depression symptoms, self esteem, emotional stress with husband. The study inquiries are:

1. What is the relationship between body image and depressive symptoms?

2. What is the relationship between body image and self esteem?

3. What is the relationship between body image and emotional distress with the husband?

4. Can body image be predicted by depressive symptoms, self esteem and emotional stress with the husband?

\section{Review of Related Literature Body Image}

The author believes that the body image, is a cognitive and mental image that the person has made of his body worse in his appearance or in his inner feelings, and may be accompanied by positive feelings or negative attitudes about that mental image of the body.

Body image was characterized concisely by (Dropkin, 1999) as "the dynamic impression of one's own substantial appearance, capacity, and sensations and in addition sentiments related with this perception (Hagedoorn et al., 2008).

The body image is described as a critical psycho-social issue for breast cancer patients, especially those who have mastectomy. this leading to a feeling of breast cancer patients anxious and depressed due to physical changes that breast cancer patients can undergo due to illness and surgeries (Dropkin, 1997). 
the author believes that the breast cancer patient is in a state of severe psychological conflict, before the mastectomy as the content of this conflict the conflict between the consequences of the disease and the need for mastectomy and the results of this eradication on the external appearance, although when the patient decides to eradicate the breast, the result is regret and concern over appearance in front of others.

The body image that individuals have of themselves even influences their practices. eradication of one or the two breasts is regularly related with changes in mental picture, decreased sexual fascination, nervousness, gloom, sentiments of misery, feeling of being dismantled, blame, dread of repeat, , and inevitably Thinking of suicide (Bagheri \& Mazaheri, 2015).

Besides, and from the point of The view of psychology, body image is a build that suggests how one considers furthermore, feels and how one Realize and acts in connection to one's very own body (Herranz, Manos, Bueno, \& Mateos, 2008).

It is expected that there will be a relationship between the removal of one breast and the body image for women. She may suffer feelings of loss of one of her breasts and feelings of anxiety and frustration about how they appear to other especially the husband or her partner (Dye, 2008).

In addition to the society considers women's breasts as symbols of femininity and sex, so any damage to the breast leads to feelings of anxiety. Those feelings that may lead to despair and pessimism of life because of the disorder perception of the body image (Rezaei et al., 2016).

The previous studies emphasizes that patients with breast cancer can experience changes in body image, self-concept, emotions, behavior, family dynamics, and the roles of the patient and her family (Kocan \& Gürsoy, 2016)

\section{Depressive Symptom}

Depression Symptoms usually include feelings about the self that may contain negative feelings about the body image. This is because depression may increase the susceptibility to criticism of real or imagined weakness in order to achieve positive awareness of body image. There is also a relationship between depressive symptoms and a negative body image among young women(Almeida, Severo, Araújo, Lopes, \& Ramos, 2012).

Previous studies have shown that nearly a third of breast cancer patients are more likely to experience psychological stress. Depression also spreads among breast cancer patients, depending on the nature of the sample and the method of diagnosis and assessment of depression (Purkayastha et al., 2017).

\section{Emotional Stress}

The emotional experience is a very complex human experience. Although emotional experiences such as feeling happy or feeling sad may seem obvious. Now that understanding feelings requires more ability to understand the human psyche and its depths. Emotional motivation also leads to behavioral, physiological and personal responses (Conley, Bishop, \& Andersen, 2016)

There is clear awareness that there is no doubt that the diagnosis and treatment of cancer does not only affect patients, but also includes the families of cancer patients, their friends and their husbands, as well as the people who provide them with care (Girgis \& Lambert, 2009) 
Emotional stress is called the sixth vital sign in cancer care. The emotional stress of cancer patients is also of an important nature because there is a relationship between the high level of emotional stress and low compliance with cancer treatment (DiMatteo, Lepper, \& Croghan, 2000),

The author believes that the emotional pressure of the wife who suffer from mastectomy after the cancer is due to the husband because it depends on it a lot in the sense of femininity, because the husband may feel the wife is upset and distaste due to mastectomy, which causes the wife's feeling of emotional pressure, which leads to strained sexual relationship.

The effect of mastectomy on the emotional relationship between the spouses through the effect of the shape of the breast and its effects on the body of a large body of the wife and can contribute to low self-esteem and may cause depression as a result of the loss of an influential part of a special character in her sexual relations with her husband (Fobair et al., 2006)

The author believes that the breast is a strong symbol of female femininity and the loss of this breast negatively effects on the husband's perception to body image of his wife, which may be this part of the body a strong cause of sexual excitement in many of the husband, leading to disappointment by couples, To the wife's feeling of emotional pressure because she feels that their husbands did not become sexual desire as it was in the past.

\section{Self Esteem}

Many psychological theories indicate that self-esteem is one of the basic needs or drivers in humans. Maslow indicated that self-esteem is divided into quality, the first being internal self-esteem, and the second being self-esteem by others. Maslow also explained that self-esteem is one of the goals of normal people, as failure to achieve self-esteem may lead to the appearance of abnormal psychological symptoms (Abamara Nnaemeka, Agu Solomon, Gangopadhyay, Sahni, \& Esther, 2014) Self-esteem is one of the most important self-assessments of an individual. Because it is considered a basic component of mental health. Also, the high level of self-esteem is linked to the improvement of performance in many aspects of personality such as professional success, social and emotional relationships, well-being and positive perceptions on the part of their peers, perseverance in the face of failure, and improving coping skills and self-organization (Kling, Hyde, Showers, \& Buswell, 1999). Carl Rogers, a pioneer in the humanities school of psychology, pointed out that many psychological problems faced by humans are low self-esteem (Greenberg, 2008)

Self-esteem is related to a person's physical appearance, for example when a woman goes down of level of self-esteem that she feels is not satisfied with the image of her body, and on the contrary, we find women who have not satisfied with the image of her body and we see her feel a decrease in the level of self-esteem. In addition, there is a relationship between high self-esteem and some psychological benefits, such as positive influence, the ability to normal psychological compatibility, and the ability to cope of psychological stress (Stapleton, Crighton, Carter, \& Pidgeon, 2017)

Self-esteem is intrinsically linked to ideas related to a person's body, so that the physical appearance has been consistently found as the first indication of self-esteem in many people (Huebscher, 2010)

\section{Methodology}

\section{Participants}

Participants in the current study were (33) women aged from 37 to 49 years ( $M=42.6)$ who had surgery for mastectomy as a result of breast cancer in the Arab Republic of Egypt. The objectives of 
the study were explained to the patient's husbands so that the scales are applied in an informed manner. The author confirmed that all members of the study sample had undergone surgery to mastectomy as a result for breast cancer. in addition to author also confirmed that all members of the sample are still married and their husbands were still living with them.

\section{Measures}

Body Image Scale: The author has prepared a body image scale included 20 items with 4-point Likert scale. The items focused on (the sense of physical and sexual attractiveness, feeling of body deformity, avoid seeing the body naked, avoiding appearance of others, anxiety of scars scattered in the body, low level of femininity). A higher score indicates that the individual is rated negative perception of the body image. For Body image scale, internal consistency validity for scale items has varied from (0.43 - 0.77) and Split half reliability is $(R=0.69)$

Self Esteem Scale: The author used the self-esteem scale developed by Rosenberg (Rosenberg, 1965). The scale consists of 10 items with 4-point Likert scale and it is the most widely used instrument to measure self-esteem despite certain negative criticism. A higher score indicates that the individual is rated positively self esteem. Internal consistency validity for scale items has varied from (0.52 - 0.76$)$ and Split half reliability is $(R=0.71)$

Depressive Symptom Scale: The author has prepared a depressive symptom scale included 24 items with 4-point Likert scale. The items focused (performance Low, isolation love, pessimistic view of life, despair feeling, sleep and eating disorders). The author presented the scale to a three number of specialized professors psychiatry and abnormal psychology field to identify the appropriateness of the scale items for the target for which the scale was prepared. A higher score indicates that the individual is rated increased depressive symptoms., depressive symptom scale internal consistency validity for scale items has varied from $(0.39-0.79)$ and Split half reliability is $(R=0.67)$

Emotional Stress with Husband Scale: The author has prepared an Emotional stress with the husband scale included 20 items with 4-point Likert scale. The items focused (Emotional relationship disorder, jealousy, intimate and sexual relationships, romance, lack of respect for feelings). The author presented the scale to a three number of specialized professors' social psychology and mental health field to identify the appropriateness of the scale items for the target for which the scale was prepared. A higher score indicates that the individual is rated defect in the emotional relationship with the husband. emotional stress with husband scale, internal consistency validity for scale items has varied from0.32 - 0.70 and Split half reliability is $R=0.66$

\section{Results and Discussion}

Results related to the first question

To answer the first question "Is there any statistically significant relationship between body image and depressive symptoms?" Correlation coefficient was calculated. Results are shown in table 1. 
INTERNATIONAL JOURNAL OF ACADEMIC RESEARCH IN PSYCHOLOGY

Vol. 7, No. 1, 2020, E-ISSN: 2312-1882 @ 2020 KWP

Table 1: Correlation coefficient and statistical significance between body image and depressive symptoms.

\begin{tabular}{ccc}
\hline Variables & Correlation Coefficient & \multirow{2}{*}{ Significance } \\
\cline { 2 - 2 } & Depressive Symptoms & \\
\hline Body Image & 0.409 & 0.05
\end{tabular}

Table (1) shows that there is a statistically significant positive relationship $(R=.409)$ between body image and depressive symptoms at $(\alpha=0.05$. This indicates that the higher the level of depressive symptoms, the more negative the body image increases, while if the level of depressive symptoms decreases, the lower the level of negative body image decreases.

The author believes that the depressive symptoms that appear to breast cancer patients are due to the feeling of losing something that is considered the strongest symbol of womanhood and thus its loss leads to a feeling of disappointment. Also, this loss leads to feelings of sadness and despair, which contributes to an increase in the negative feeling of the body image, especially after mastectomy. Also, multidisciplinary health care services related to physical attractiveness and femininity after mastectomy may enhance the improvement of depressive feelings and increase the quality of life, thereby reducing negative feelings of body image.(Begovic-Juhant, Chmielewski, Iwuagwu, \& Chapman, 2012)

The depressive symptoms are the most common symptoms associated with breast cancer and have a negative impact on the mental health of breast cancer patients (Cordero et al., 2015). Depressive symptoms lead to a decrease in the level of optimism that contributes to increasing the level of death anxiety (Ahmad \& Gaber, 2019).

Failure to diagnose symptoms of mood disorder, especially depression, in breast cancer patients after the mastectomy stage. This affects the acceptability of treatment and the level of optimism in survival. The feeling of losing the value of life due to mastectomy is one of the most important manifestations of femininity, especially for the husband. These feelings lead to a negative perception of the body image.(Reich, Lesur, \& Perdrizet-Chevallier, 2008)

\section{Results Related to the Second Question}

To answer the first question "Is there any statistically significant relationship between body image and self esteem?" Correlation coefficient was calculated. Results are shown in table 2.

Table 2: Correlation coefficient and statistical significance between body image and self -esteem.

\begin{tabular}{ccc}
\hline Variables & Correlation Coefficient & Significance \\
\cline { 2 - 2 } & self esteem & \\
\hline Body Image & -0.376 & 0.05 \\
\hline
\end{tabular}

Table (2) shows that there is a statistically significant negative relationship ( $R=-.376)$ body image and self esteem at $(\alpha=0.05$.

This indicates that the higher the level of self esteem, the more negative the body image decreases, while if the level of self esteem increases, the lower the level of negative body image decreases. Selfesteem is one of the most important elements of psychological construction, which helps the individual in the face of bad events in this life (Ghali et al., 2017) 
The author believes that the level of self-esteem of the individual contributes to facing stressful situations. Among patients with cancer, mastectomy is one of the most difficult stressful situations for breast cancer patients. Therefore, the high self-esteem of breast cancer patients after mastectomy is one of the reasons the patient feels self-squatting. In addition to being able to manage stress and overcome difficult situations, the patient will thus feel a positive awareness of the image of the body as a result of the high level of self-esteem (Kosir et al., 2001)

\section{Results Related to the Third Question}

To answer the first question "Is there any statistically significant relationship between body image and emotional stress with husband?" Correlation coefficient was calculated. Results are shown in table 3 .

Table 3: Correlation coefficient and statistical significance between body image and emotional stress with husband.

\begin{tabular}{|c|c|c|}
\hline Variables & $\begin{array}{c}\text { Correlation Coefficient } \\
\begin{array}{c}\text { Emotional stress with } \\
\text { husband }\end{array}\end{array}$ & Significance \\
\hline Body Image & .429 & 0.05 \\
\hline
\end{tabular}

Table (3) shows that there is a statistically significant positive relationship( $R=.429)$ between body image and emotional stress with husband at $(\alpha=0.05$.

This indicates that the higher the level of emotional stress with husband, the more negative the body image increases, while if the level of emotional stress with husband decreases, the lower the level of negative body image decreases.

The researcher believes that there are disorders of sexual and emotional relations between husband and wife due to mastectomy. Because the breast is considered one of the most important elements in the emotional and sexual relations between the spouses. Consequently, it can be said that patients with breast cancer live in pressures of two dimensions, the first of which is the pressure of mastectomy and the second is the emotional pressure with the husband, which negatively affects on the body image perception.

\section{Results Related to the Fourth Question}

To answer the fourth question "Can the depressive symptoms, self esteem and emotional stress with husband predict body image?" Regression and prediction coefficients (stepwise) were calculated. Results are shown two models in table 4 and table5. 
Model 1 Table 4: Indicates that emotional stress with husband predict body image.

\begin{tabular}{cccccc}
\hline Model1 & \multicolumn{2}{c}{$\begin{array}{c}\text { un standardized } \\
\text { Coefficients }\end{array}$} & $\begin{array}{c}\text { Standardized } \\
\text { Coefficients }\end{array}$ & & t \\
\cline { 2 - 4 } & B & Std. Error & Beta & & \\
Constant & 30.66 & 7.04 & --- & 4.35 & .000 \\
$\begin{array}{c}\text { Emotional stress } \\
\text { with husband }\end{array}$ & .385 & .173 & .429 & 2.22 & .036 \\
\hline
\end{tabular}

Table No. 4 indicates that the first model of the predictive relationship between body image and both self-assessment and depressive symptoms and emotional pressures with the husband has found that emotional pressure with the husband predicted the body image in post- mastectomy for breast cancer patients.

This is because the partner or husband is one of the most important persons who are supposed to provide psychological and social support to wives, especially in post-mastectomy stage. The decrease of the partner's romantic support for the wife contributes to creating a negative perception of the body image of the wives (Weller \& Dziegielewski, 2005)

Thus, disturbances arise in that relationship, which negatively affects on body image of wife. This is because the wife believes that the loss of one of her breasts is the reason for the disturbance of the relationship between her husband or her partner, which contributes to disturbing the image of the body (Weller \& Dziegielewski, 2005)

Model 2 Table 5: Indicates that depressive symptoms and emotional stress with husband predict body image.

\begin{tabular}{|c|c|c|c|c|c|}
\hline \multirow[t]{2}{*}{ Model1 } & \multicolumn{2}{|c|}{$\begin{array}{l}\text { un standardized } \\
\text { Coefficients }\end{array}$} & \multirow{2}{*}{$\begin{array}{c}\begin{array}{c}\text { Standardized } \\
\text { Coefficients }\end{array} \\
\text { Beta }\end{array}$} & \multirow[t]{2}{*}{$t$} & \multirow[t]{2}{*}{ Sig. } \\
\hline & B & Std. Error & & & \\
\hline Constant & 16.21 & 9.40 & ---- & 1.72 & .099 \\
\hline $\begin{array}{c}\text { Emotional } \\
\text { stress with } \\
\text { husband }\end{array}$ & .389 & .160 & .433 & 2.42 & .024 \\
\hline $\begin{array}{l}\text { Depressive } \\
\text { Symptoms }\end{array}$ & .358 & .168 & .381 & 2.13 & .045 \\
\hline
\end{tabular}

Table (5) indicates that the second model of the predictive relationship between body image and both self-esteem and depressive symptoms and emotional stress with the husband has found that emotional stress with the husband and depressive symptoms predicted the body image in postmastectomy for breast cancer patients.

The risk of higher sexual dysfunction with partner in patients with breast cancer may be partly due to a set of possible pathways through which sexual performance is affected after breast cancer treatment. Perhaps most importantly, a woman's sexual life includes not only the ability to engage in sexual activity, but also feelings about an individual's body and his thoughts about body image and femininity. Given that sexual activity is closely related to the image of the body, any disorder in the body image caused by disorders in the relationship with the partner may also lead to disorders in sexual performance, and then the emotional and sexual pressures with the partner predicted the body image for the breast cancer patients (Weller \& Dziegielewski, 2005). 
The researcher believes that the emotional stress with the partner, which are represented in the decrease in psychological and emotional support, the refusal of sexual relations, and the lack of acceptance after mastectomy, which leads to an increase in negative perceptions for body image, and therefore it can be said that the image of the body can be predicted in breast cancer patients through both the emotional stress with the husband and depressive symptoms (Weller \& Dziegielewski, 2005).

Depression is also a common factor in cancer patients in general and breast cancer patients in particular. This is because breast loss is the most difficult feelings a woman can feel because the breast is a symbol of femininity and sexual arousal. Hence, its loss is the major disappointment felt by patients with breast cancer, especially in the post-mastectomy phase, which leads to body image disorders, and therefore, symptoms of depression is one of the predictions of the body image of breast cancer patients.

Through the results of the study's findings, the author believes that it is necessary, in addition to the medical treatment for breast cancer patients, that there are psychological treatment programs based on preparing partners in the marital relationship, and reducing symptoms of depression in cancer patients, which may contribute to accepting treatment and maintaining the love life values and optimism.

\section{Conclusion}

The body image is one of the factors affecting the psychological construction of breast cancer patients, especially after mastectomy. The current study showed that the body image is associated with some psychological variables such as depression, self-esteem and emotional stress with the partner or husband. The author suggests, through the predictive results of the current study, the need to prepare counseling programs for breast cancer patients who conducted the mastectomy process, so that these programs include the need for self-esteem and counseling of partners or husband in psychological interaction with their wives, in addition to alleviating the level of depression symptoms.

Finally, the author recommends that future studies in this topic should include knowledge of the impact of counseling programs for breast cancer patients and their spouses to reduce the level of depression and emotional stress.

\section{References}

Ahmad, A. A., \& Gaber, O. H. (2019). The Relationship between Death Anxiety, Level of Optimism and Religiosity among Adult Cancer Patients: A Predictive Study. International Journal of Psychological Studies, 11(1).

Almeida, S., Severo, M., Araújo, J., Lopes, C., \& Ramos, E. (2012). Body image and depressive symptoms in 13-year-old adolescents. Journal of paediatrics and child health, 48(10), E165E171.

Arroyo, J. M. G., \& López, M. L. D. (2011). Psychological problems derived from mastectomy: a qualitative study. International journal of surgical oncology, 2011.

Aryaie, M., Bagheri, D., Ozouni-Davaji, R. B., Mostafshar, S., Bolukat, E., \& Khodabakhshi, R. Association of Anxiety, Depression, and Body Image Disorder with Pain-Related Disability in Post-Mastectomy Breast Cancer Patients. JCBR, 1(4), 26-30. 
INTERNATIONAL JOURNAL OF ACADEMIC RESEARCH IN PSYCHOLOGY

Vol. 7, No. 1, 2020, E-ISSN: 2312-1882 @ 2020 KWP

Bagheri, M., \& Mazaheri, M. (2015). Body image and quality of life in female patients with breast cancer and healthy women. Journal of Midwifery and Reproductive Health, 3.

Begovic-Juhant, A., Chmielewski, A., Iwuagwu, S., \& Chapman, L. A. (2012). Impact of body image on depression and quality of life among women with breast cancer. Journal of psychosocial oncology, 30(4), 446-460.

Cordero, A. M. J., Villar, M. N., Sánchez, N. M., Pimentel-Ramírez, M. L., García-Rillo, A., \& Valverde, G. E. (2015). Breast cancer and body image as a prognostic factor of depression: a case study in México City. Nutricion hospitalaria, 31(1).

Conley, C., Bishop, B., \& Andersen, B. (2016). Emotions and emotion regulation in breast cancer survivorship. Paper presented at the Healthcare.

Cordero, M. J. A., Villar, N. M., Sánchez, M. N., Pimentel-Ramírez, M. L., García-Rillo, A., \& Valverde, E. G. (2015). Breast cancer and body image as a prognostic factor of depression: a case study in México City. Nutricion hospitalaria, 31(1), 371-379.

D'antonio, L. L., Long, S. A., Zimmerman, G. J., Peterman, A. H., Petti, G. H., \& Chonkich, G. D. (1998). Relationship between quality of life and depression in patients with head and neck cancer. The Laryngoscope, 108(6), 806-811.

Diji, A. K.-A., Moses, M. O., Asante, E., Agyeman, Y. N., Duku, J., \& Agyeiwaa, S. A. (2015). Life with Female Partners after Mastectomy: the Perception of Ghanaian Men. International Journal of Applied, 5(4).

DiMatteo, M. R., Lepper, H. S., \& Croghan, T. W. (2000). Depression is a risk factor for noncompliance with medical treatment: meta-analysis of the effects of anxiety and depression on patient adherence. Archives of internal medicine, 160(14), 2101-2107.

Dropkin, M. (1997). Postoperative body image in head and neck cancer patients. Quality of Life $-A$ Nursing Challenge, 5, 110-113.

Dye, S. M. (2008). Factors affecting the impact of breast cancer on body image and sexual functioning. The University of North Carolina at Chapel Hill,

Fang, S.-Y., Chang, H.-T., \& Shu, B.-C. (2014). Objectified body consciousness, body image discomfort, and depressive symptoms among breast cancer survivors in Taiwan. Psychology of Women Quarterly, 38(4), 563-574.

Fang, S.-Y., Lin, Y.-C., Chen, T.-C., \& Lin, C.-Y. (2015). Impact of marital coping on the relationship between body image and sexuality among breast cancer survivors. Supportive Care in Cancer, 23(9), 2551-2559.

Fingeret, M. C., Teo, I., \& Epner, D. E. (2014). Managing body image difficulties of adult cancer patients: lessons from available research. Cancer, 120(5), 633-641.

Fobair, P., Stewart, S. L., Chang, S., D'onofrio, C., Banks, P. J., \& Bloom, J. R. (2006). Body image and sexual problems in young women with breast cancer. Psycho-Oncology, 15(7), 579-594.

Gardikiotis, I., Azoicăi, D., Popa, M., Manole, A. M., \& lorga, M. (2015). The Impact of Body Image and Self-Perceived Physical Ability on the Well-Being after Mastectomy without Reconstruction. Jurnalul de Chirurgie, 11(4).

Ghali, H., Fendri, S., Ayedi, I., Bougmiza, I., Ammar, A., Belaid, I., . . Bouafia, N. (2017). Perception of Self-esteem and Body Image among Women with Breast Cancer of a University Hospital in Tunisia. Journal of Advances in Medicine and Medical Research, 1-12. 
INTERNATIONAL JOURNAL OF ACADEMIC RESEARCH IN PSYCHOLOGY

Vol. 7, No. 1, 2020, E-ISSN: 2312-1882 @ 2020 KWP

Girgis, A., \& Lambert, S. (2009). Caregivers of cancer survivors: the state of the field. Paper presented at the Cancer Forum.

Gomes, N. S., \& Silva, S. (2013). Evaluation of the self-esteem of women who had undergone breast cancer surgery. Texto Contexto Enferm, 22, 509-516.

Greenberg, J. (2008). Understanding the vital human quest for self-esteem. Perspectives on psychological science, 3(1), 48-55.

Hagedoorn, M., Sanderman, R., Bolks, H. N., Tuinstra, J., \& Coyne, J. C. (2008). Distress in couples coping with cancer: A meta-analysis and critical review of role and gender effects. Psychological bulletin, 134(1), 1.

Hamilton, S. R. (2008). A relationship between perceived body image and depression: How college women see themselves may affect depression. Student Journal of Psychological Science, 1(1), 13-20.

Hardman, A., Maguire, P., \& Crowther, D. (1989). The recognition of psychiatric morbidity on a medical oncology ward. Journal of psychosomatic research, 33(2), 235-239.

Heidari, M., \& Ghodusi, M. (2015). The relationship between body esteem and hope and mental health in breast cancer patients after mastectomy. Indian journal of palliative care, 21(2), 198.

Herranz, J. S., Manos, D., Bueno, M. J., \& Mateos, N. (2008). Body image and self-esteem in women with breast cancer participating in a psychosocial intervention program. Psychology in Spain (12), 13-25.

Holsen, I., Kraft, P., \& Røysamb, E. (2001). The relationship between body image and depressed mood in adolescence: A 5-year longitudinal panel study. Journal of Health Psychology, 6(6), 613-627.

Huebscher, B. C. (2010). Relationship between Body Image and Self Esteem Among Adolescent Girls. The Journal Of Social Psychology, 146, 15-30.

Jafari, A., Goudarzian, A. H., \& Nesami, M. B. (2018). Depression in women with breast cancer: a systematic review of cross-sectional studies in Iran. Asian Pacific journal of cancer prevention: APJCP, 19(1), 1.

Junne, F., Zipfel, S., Wild, B., Martus, P., Giel, K., Resmark, G., . . Dinkel, A. (2016). The relationship of body image with symptoms of depression and anxiety in patients with anorexia nervosa during outpatient psychotherapy: Results of the ANTOP study. Psychotherapy, 53(2), 141.

Keesing, S., Rosenwax, L., \& McNamara, B. (2016). A dyadic approach to understanding the impact of breast cancer on relationships between partners during early survivorship. BMC women's health, 16(1), 57.

Kling, K. C., Hyde, J. S., Showers, C. J., \& Buswell, B. N. (1999). Gender differences in self-esteem: a meta-analysis. Psychological bulletin, 125(4), 470.

Kocan, S., \& Gürsoy, A. (2016). Body image of women with breast cancer after mastectomy: a qualitative research. The journal of breast health, 12(4), 145.

Kosir, M. A., Rymal, C., Koppolu, P., Hryniuk, L., Darga, L., Du, W., . . . Wang, W. (2001). Surgical outcomes after breast cancer surgery: measuring acute lymphedema. Journal of Surgical Research, 95(2), 147-151.

Latifi, M., Salimi, S., Barahmand, N., Fahimnia, F., \& Farsani, L. A. (2018). Postmastectomy Information Needs and Information-seeking Motives for Women with Breast Cancer. Advanced biomedical research, 7. 
INTERNATIONAL JOURNAL OF ACADEMIC RESEARCH IN PSYCHOLOGY

Vol. 7, No. 1, 2020, E-ISSN: 2312-1882 @ 2020 KWP

Leite, M. A. C., Nogueira, D. A., \& Terra, F. D. S. (2015). Evaluation of self-esteem in cancer patients undergoing chemotherapy treatment. Revista latino-americana de enfermagem, 23(6), 10821089.

Manaf, N. A., Saravanan, C., \& ZuhrAh, B. (2016). The prevalence and inter-relationship of negative body image perception, depression and susceptibility to eating disorders among female medical undergraduate students. Journal of clinical and diagnostic research: JCDR, 10(3), VC01.

Marcus, M., Yasamy, M. T., Ommeren, V. M. V., Chisholm, D., \& Saxena, S. (2012). Depression: A global public health concern.

McClure, K. S., Nezu, A. M., Nezu, C. M., O'hea, E. L., \& McMahon, C. (2012). Social problem solving and depression in couples coping with cancer. Psycho-Oncology, 21(1), 11-19.

Nnaemeka, A. C., Agu Solomon, A., Gangopadhyay, A., Sahni, M., \& Esther, B. (2014). Relationship between Body Image and Self-esteem among female Undergraduate students of behavioural Sciences. IOSR Journal of humanities And Social Science (IOSR-JHSS), 19(1), 1-5.

Purkayastha, D., Venkateswaran, C., Nayar, K., \& Unnikrishnan, U. (2017). Prevalence of depression in breast cancer patients and its association with their quality of life: A cross-sectional observational study. Indian journal of palliative care, 23(3), 268.

Reich, M., Lesur, A., \& Perdrizet-Chevallier, C. (2008). Depression, quality of life and breast cancer: a review of the literature. Breast cancer research and treatment, 110(1), 9-17.

Rezaei, M., Elyasi, F., Janbabai, G., Moosazadeh, M., \& Hamzehgardeshi, Z. (2016). Factors influencing body image in women with breast cancer: A comprehensive literature review. Iranian Red Crescent Medical Journal, 18(10).

Schapmire, T., \& Faul, A. (2015). Cancer and older adults (65 Plus). In (pp. 527-534): Oxford University Press New York.

Stapleton, P., Crighton, G. J., Carter, B., \& Pidgeon, A. (2017). Self-esteem and body image in females: The mediating role of self-compassion and appearance contingent self-worth. The Humanistic Psychologist, 45(3), 238.

Weller, J. E., \& Dziegielewski, S. F. (2005). The relationship between romantic partner support styles and body image disturbance. Journal of Human Behavior in the Social Environment, 10(2), 7192.

Zimmermann, T. (2015). Intimate relationships affected by breast cancer: interventions for couples. Breast Care, 10(2), 102-108. 